\title{
TRANSFORMATIVE DIMENSIONS OF EDUCATIONAL CHANGE CONTEXT
}

\author{
Kristīne Niedre-Lathere, Alīda Samuseviča \\ Liepaja University, Latvia
}

\begin{abstract}
Nowadays in the changeable life conditions it is essential to analyse and understand the synergy of intervention sets for a successful procedure of educational processes in order not to create conditions and situations when incompatibility of opinions and points of view in the action and outcomes can be noticed, which is hard to be justified with the quality indicators and positive performance. This applies both to the practising teachers' capacity arsenal and the need for teacher training programme renewal. The focus of responsibility of socialization agents' interaction, their needs and values are changing in the educational cultural space and organization. In pedagogy and its processes there has always been the risk of resilience in changing the paradigms of subjects' thinking which is deepened in the transformation conditions by the presence of digitalization. The authors of the article analyses how the educational development tendencies are related to the need for quality cooperation, attitude and personal responsibility issues during the teacher training process. The goal of the research is to study, analyse and model the change agent strategies and educational reform implementers' professional competences for the development of pedagogical components of transformable quality cooperation in the teacher training process renewal.

In the publication the aspects of the education system have been raised, analysing the current offer of the teacher training study programmes and their quality, emphasizing the impact of the socio-economic status, as well as the significance of school as an organizational culture, the need for professional pedagogical self-development motivation and compliance of the educational standards and content settings with the reforms. The data obtained during the pedagogical practice confirm that the vision of the potential action is not sufficient, there have to be the strategies of Specific Measurable Relevant and Time-bound (SMART) model which help to transform the current approaches and quality education process in development. Unfortunately, it has been proven in practice that lots of intentions to improve the education system cannot be implemented successfully, as the platform of the processes and activities to be implemented have not been in synergy with the education policy implementers and decision makers. The reason for that is the lack of interests, confidence, motivation and awareness of risks for all agents involved in the process of changes: teaching staff, students, pupils, teachers and parents.
\end{abstract}

Keywords: agents, cooperation, education, qualities, risk, strategy, transformation. 


\section{Introduction}

Education is not the same as schooling. "Education is not a linear process that prepares for the future; actually, it develops talents and perceptual abilities due to which we are able to live the best life right now and create the best possible future" (Robinsons, 2013, 23). One has to admit that the educational process is both destructive and preservative in its nature, which is restricted in time and space. From the aspect of educational philosophy Nietzsche already lived in his life perception by the principle if one knows Why, then they also know How to live, get educated and create their own professional career. The issue of the $21^{\text {st }}$ century debate on education To Whom, Why and How does not have merely a theoretical context any longer. It is clear that education, economics, labour market, politics, social harmony are a transversal process which influences every individual's development and growth. In the theory and research data analysis it has already been proved that planning of the educational process, observance of the principle of succession and longitudinality promote growth of subjects involved in the educational process. It has been proved by several countries: Australia, Finland, South Korea, Scotland and Singapore, implementing the transformation of the education system, highlighting the shift of mindset and processual paradigms and approach at all intervention levels: administrative, political and in teacher training programmes. Logically, transformative procedures, interactions and rapprochement of all these processes happen simultaneously there. The global experience confirms that the set educational standards and principles are implemented into practice, bearing into mind every individual's health, prosperity, wellbeing, and socio-economic impact in the future.

\section{The purpose of the paper}

The versality of the educational process also includes in itself the presence of risk at all levels. The risk is not there because the teacher may not be sufficiently qualified without implementing pedagogical practice based on scientific evidence, not because the pupils would work inefficiently due to a distinct lack of motivation to learn, but rather because education is not a bucket which has to be filled up, but rather a fire which has to be kindled. The risk is there because education in not an interaction amongst robots, but socially live judgemental beings. The pupil is not an object of things and order, but rather a subject of co-responsibility for action, engagement and processual development. Technologies of education are not merely a platform, where the contributor has to be in constant synergy with the outcomes. 
Expectations the society expect from teachers are the process of an unpredictable risk-free education acquisition. Implementation of a stable - mutually aligned and efficiently monitored reform is desired by both education policy makers, politicians, media, society and also organizations that analyse the processes and quality indicators happening in the sector, for instance the Organisation for Economic Co-operation and Development (OECD) and the World Bank. Just these organizations are willing to promote attitudes towards a strong, safe and predictable/forecastable education. Education is more and more often being constructed as an efficient solution to a pre-defined learning assignment.

Resistance to risk permeates the space of modern education, causing increasingly more complicated conditions for the teacher, implementing anew education content in the distance learning process. In its turn, education policy makers analyse the rating results and learning achievements at a national, municipal and school administration level, which can easily be interpreted in comparative categories at the municipal and national level, losing the aspect of reality that in the learning process not everything is a direct identification of data or it can be performed at a very high multidimensional goal setting in the achievement of education quality indicators (Biesta, 2016, p. 4).

\section{Method}

In the context of the empirical study, a survey of the 25 school administrative leading experts' opinions of Liepaja Municipal Education Department was carried out with the help of the Wordle visual diagram formation tool, naming the most characteristic set of concepts, in order to find out the most characteristic values of educational processes of the respondents involved in the research at the level of education supervision. The outcomes of the survey have been systematized and collated in Figure 1.

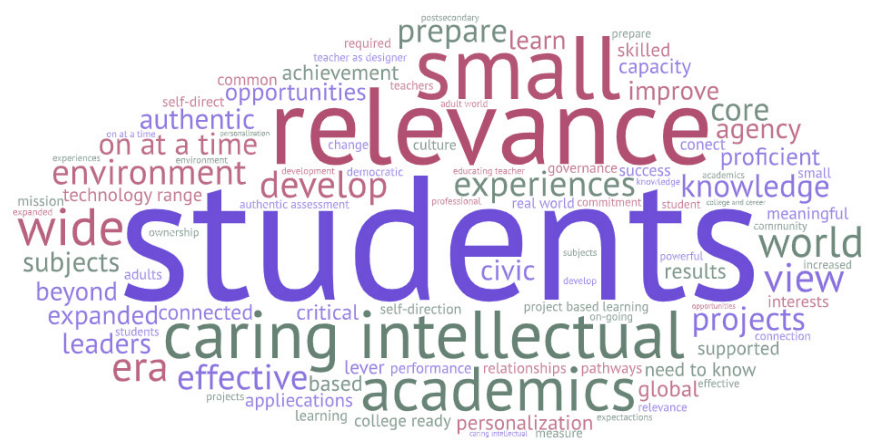

Figure 1. Values describing the educational process 
As it can be seen in Figure 1, it can be concluded that the results of the diagram highlight and escalate the need for a pupil-centred process, significance of authentic projects, respect of pupils' interests, relevance of mutual pedagogical relations as the most essential factors of impact and success in the learning success promotion and personal growth.

Through the empiric process the set of questions were asked to selected group of professionals in education, revealing their most relevant aspects, habits, virtues in educational process to demonstrate high standards in professional achievements. As a result of the remote interviews, observations and discussions with the representatives of 15 comprehensive school administration, teacher staff, directors of teacher training programmes, a unified ecosystem model of the pedagogical process has emerged based on Trilling \& Fadel concept (Trilling, Fadel, 2009):

1. Learning - deeply engaging, personalized, and collaborative learning motivated by relevant questions and deep inquiry, problems and the design of creative solutions, and real-world issues and challenging projects, all with a focus on high-quality student work.

2. Teaching - teachers as learning designers, model learners, mentors, guides, and school leaders

3. Evaluation - student work evaluated through public presentations and by a variety of authentic performance assessments incorporated into everyday learning

4. Culture/climate - for both students and educators, a professional culture of high expectations, responsibility, ownership, and self-direction; and a personal culture of caring, respect, trust, cooperation, and community

5. Development - teacher and student development focused on improving the quality of student work through collaboration and embedded coaching, modelling, mentoring, and leadership

6. Tools - pervasive use of technology and other learning resources to support Deeper Learning outcomes and practices.

The model of the educational process includes in itself three key dimensions of activity: qualification, socialization and subordination, providing all intervention agents with knowledge, skills and disposition (Biesta, 2016). An appropriate qualification enables participation in the planning and implementation of the educational process, creating the conditions and environment in which the individual becomes as an existing social, cultural and socially active citizen with their identity, participates in socialization processes, expressing their attitude, forms and cultivates their position and stance in the society in compliance with generally accepted prevailing norms without losing their personal freedom and without harming socio-emotional intelligence. 
Considering pandemic circumstances the authors of the paper in ZOOM discussions with students and teachers revealed existing gaps between the pupils and teachers' diverse understanding on the impact of socio-emotional skills in the learning process. A personalized approach of the learning process is the Skola 2030 characteristic. It is a tool to reveal the teacher's irreplaceable role in the pupils' development performance, accelerating everybody's individual growth. Modern learning experience design should centre attention on the needs of students; approaching learning as a fluid, holistic, seamless set of experiences. Modern learning experience designs include inquiry-based learning, project-based learning, challenge-based learning, phenomenon-based learning, and personalized learning (Cavanaugh, 2016).

In the pedagogical practice in the context of topical changes, analysing the teacher training programmes and their content, it is important to be aware of the 3 most crucial factors transforming the educational environment:

Collaboration/communication platform, which develops in pupils the skill to collaborate with each other and the teacher; enables the teacher to develop customizable lesson plans, providing the opportunity for a realistic personalized feedback.

Role and impact of the artificial intellect on the learning process and paradigm shift in thinking in all stakeholders' interaction in the target-orientated content implementation.

The mixed reality of the pedagogical environment which creates immersive learning experiences and develops in pupils the growth of the cognitive and socio-emotional intelligence (Trilling and Fadel, 2009) (see Fig. 1).

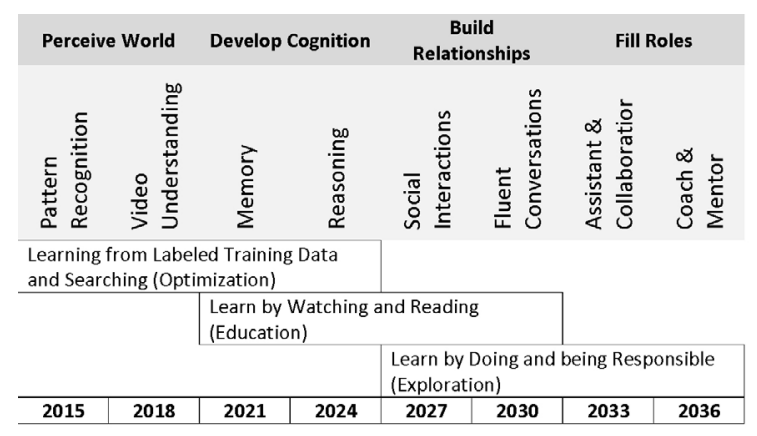

Figure 1. Approach of deep learning

In the information society any human is situated in a constant disordered flow of information where the digital age triggers challenges and 
becomes as an important indicator of the modern social capacity which is the base for the formation of a new learning culture, diminishing the gap between the academic knowledge and topical needs of the society in the intergenerational interaction, causing constant risks of growth, whose prevention depends on productive and individualized learning strategies at all levels of education. In the development and approbation of the innovative teacher training programme, the above defined challenges and preconditions of the information society have to become as the fundamental principle of sample study planning which harmonize and increase the capacity of human resources in the self-educating and self-development perspectives. Developing a new learning culture, it is important to highlight Svarcs's cognition: "Thinking capacity which takes to knowledge is a lot more important than the volume of the accumulated information" (Švarcs, 2017, p.38).

When organizing the pedagogical process, the balance has to be found among three domains: the load of logistics - related to the synchronization of different tools, e-platforms, software applications for the improvement of the operational efficiency; cognitive load - amount of information that should be memorized in order to be able to operate with digital gadgets (remembering multiple different passwords and access codes); work load what requirements have to be observed both by the teacher when teaching efficiently and the pupil when learning efficiently in order to reach the goal with the volume and depth of the set tasks (see Fig. 2).

The identification of the previously set and raised criteria characterizing the pedagogical process in the innovatively developed educational programmes facilitates not only the asking of rhetorical questions, but also a purposeful discussion about the domains of programme transformation.

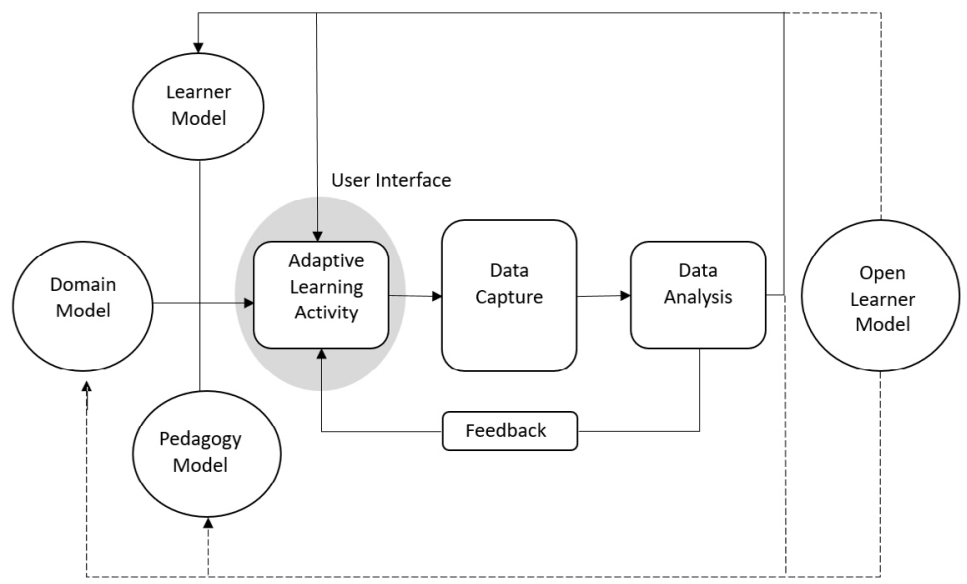

Figure 2. Structure of Intelligence Monitoring System 


\section{Conclusions}

The multimodality of the pedagogical approach reveals efficient teaching and learning approaches based on scientific theories and experts' findings. Based on the challenges encountered during the pedagogical practice, the authors highlight the importance of the intelligent mentoring/tutoring system in the development of pupils, students' personal performance (Fadel, 2019). Knowledge on the approach of the intelligent mentoring system and its operational strategies enables us to structure the educational process in the proximal development zone, application of transversal skills, cognitive load adequacy and provision of formative feedback.

Modern educational content based on the principles of deep learning must be aimed at the possibility of knowledge transfer, motivation-promoting, content-wide and versatile acquisition of knowledge and skills:

- Versatility, for robustness to face life and work.

- Relevance, for applicability, and student motivation.

- Transfer for broad future actionability.

Developing it through:

- Selective emphasis on important areas of traditional knowledge.

- The additional of modern knowledge.

- A focus on essential content and core concepts.

- Interdisciplinarity, using real-world applications.

- Embedded skills, character, and meta learning into the knowledge domains.

It is vital to find the balance between vocational and social life dimensions in the open education system. Looking for and finding the balance, developing educational strategies directed towards the personality and obtaining the experience of an individualized approach, the wellbeing of everybody involved in the educational process improves, which accumulates energy, reveals the inner growth resources and causes vitality, which harmonizes with the personal and social life aspects.

\section{References}

Biesta Gert, J. J. (2016). The Beautiful Risk of Education. Routledge.

Cavanaugh, C. (2016). Learning with Technology. Amazon.de: Harris, R. Carl: Fremdsprachige Bücher.

Holmes, W., Bialik, M., Fadel, C. (2019). Artificial Intelligence in Education: Promises and Implications for Teaching \& Learning. The Centre for Curriculum Redisign, Boston.

Robinsons, K. (2013). Ne tikai ar prātu. Mācāmies būt radoši/ Not only with Brain. Let's Learn to Be Creative / Rìga: Zvaigzne ABC. 
Švarcs, D. Dž. (2017). Vērienīgās domāšanas spēks/Power of Comprehensive Thinking/. Rīga: Zvaigzne ABC.

Trilling, B. and Fadel, C. (2009). 21 ${ }^{\text {st }}$ Century Skills: Learning for Life in Our Times, JohnWiley \& Sons.

University of Latvia. (2006). Frïdriha Ničes religijas filosofijas hermeneitika. Retrieved from: https://www.lu.lv/zinatne/programmas-un-projekti/petniecibas-projekti-latvijasuniversitate/2006/titans/

World Economic Forum Publication New Vision for Education: Fostering Social and Emotional Learning through Technology. Retrieved from: https://www.bcg.com/HowEducation-Technology-Can-Foster-Social-Emotional-Skills-Mar-2016_tcm-61303.pdf 